\title{
Photodynamic inactivation in the treatment of experimental herpes simplex keratitis
}

\author{
J. V. THOMAS, W. A. DUNLAP, AND A. M. RICH \\ Department of Ophthalmology, University of North Carolina School of Medicine, Chapel Hill, U.S.A.
}

Photodynamic inactivation involves the photosensitization of a biological system by a $\frac{0}{0}$. substance which serves as a light absorber for photochemical reactions in which molecular or oxygen is used. This phenomenon was seriously investigated after it was demonstrated ir that low concentrations of acridine, which had no effect on paramecia in the dark, could $\underset{\omega}{\omega}$

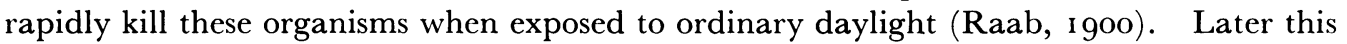
was crudely demonstrated in viruses (Perdrau and Todd, I933; Shortt and Brooks, I934). In the last decade it has been shown that certain heterotricyclic dyes could be bound irreversibly in vitro to the herpes virus. The virus was rapidly and completely inactivated when exposed to visible light. The photoactive dyes found to be most effective were $\vec{\varphi}$ neutral red, proflavine, and toluidine blue (Wallis and Melnick, I965). The mechanism of photodynamic inactivation involves the combination of a photoactive dye with the guanine base portions of the DNA. On exposure to light, this molecular complex is disrupted, causing excision of the guanine moiety. This leaves a gap in the base sequence and subsequent single strand breaks in the viral DNA (Sastry and Gordon, I966; Freifelder and Uretz, i 966$)$.

The principle of photodynamic inactivation has been recently applied to human herpes simplex lesions on skin and mucocutaneous areas (Felbar, Wallis, Smith, Melnick, and Knox, I97I). The technique of treatment consists in rupturing and unroofing early vesicular lesions, liberally applying a $0 \cdot \mathrm{I}$ per cent. solution of aqueous neutral red dye with a cotton applicator to the base of the ruptured vesicles, and then exposing the lesions to a fluorescent lamp at a distance of 6 in. for two 15 -minute periods. 9o per cent. of patients treated with light and neutral red dye reported symptomatic improvement and shortened healing time superior to that obtained by any mode of therapy previously used. In 80 per cent. of treated patients, the recurrence rates of herpes "cold sores" decreased by more than $5^{\circ}$ per cent.

These encouraging results on skin and mucocutaneous areas have led us to investigate the possibility of using photodynamic inactivation in the treatment of experimental herpes simplex keratitis. It is the purpose of this paper to report these results.

\section{Materials and method}

$36 \mathrm{New}$ Zealand white rabbits weighing from 4 to $6 \mathrm{lb}$. each were used as the experimental animals. Both corneae of each animal were cross-hatched with a i9 gauge needle. Approximately eighty $\stackrel{\mathcal{\infty}}{\rightarrow}$ strokes were made on each cornea without perforating Bowman's membrane. Each eye was then 7 inoculated with $0.2 \mathrm{ml}$. Type HF Herpes virus hominis containing $10^{4} \mathrm{TCID}_{50} / \mathrm{ml}$. on Hela cells. The lids were then closed and lightly rubbed over the cornea.

The neutral red dye was of certified grade (National Aniline). It was dissolved in distilled water $\stackrel{\mathbb{D}}{\stackrel{\Xi}{8}}$ to make a $0 \cdot 1$ per cent. solution and then passed through a $0 \cdot 22 \mu \mathrm{m}$. micropore GS filter with an 
AP 20 clarifying filter. It was stored in aluminium foil-covered bottles to protect it from the light.

Before treatment, each animal was anaesthetized with $25 \mathrm{mg}$. $/ \mathrm{kg}$. sodium pentobarbital given intravenously. The treatment procedure consisted of first applying $0 \cdot$ I per cent. aqueous neutral red dye in excess over the cornea with a glass pipette. A fluorescent lamp with two cool white I 5 watt bulbs was then placed at a distance of 6 in. from the eye for a period of 15 minutes. Right eyes were treated while left eyes remained as controls.

The rabbits were divided into two groups and the frequency of treatment was varied for each. The first group (22 rabbits) was treated on Days 3 and 4 , and the second group (14 rabbits) on Days 3, 4, 5, 6 and 7. In order to compare treated and control eyes, a modification of the Draize scoring system was devised (Draize, Woodward, and Calvery, 1944) (Table).

Table Draize scoring system

\begin{tabular}{|c|c|c|c|}
\hline \multicolumn{3}{|l|}{ Reaction } & \multirow{3}{*}{$\begin{array}{l}\text { Points scored } \\
\\
1 \\
2 \\
3 \\
4\end{array}$} \\
\hline I. Cornea & & Staining with fluorescein & \\
\hline & & $\begin{array}{l}\text { one or more pinpoint lesions } \\
\text { several lesions larger than pinpoints } \\
\text { developing dendrites } \\
\text { well-formed dendrites }\end{array}$ & \\
\hline \multirow[t]{6}{*}{ II. Conjunctiva } & $(A)$ & Redness & \\
\hline & & $\begin{array}{l}\text { vessels injected above normal } \\
\text { more diffuse, individual vessels not discernible } \\
\text { diffuse, beefy red }\end{array}$ & $\begin{array}{l}1 \\
2 \\
3\end{array}$ \\
\hline & $(B)$ & Chemosis & \\
\hline & & $\begin{array}{l}\text { any swelling above normal } \\
\text { obvious swelling with partial eversion of lids } \\
\text { swelling with lids half closed }\end{array}$ & $\begin{array}{l}\mathbf{1} \\
2 \\
3\end{array}$ \\
\hline & $(C)$ & Discharge & \\
\hline & & $\begin{array}{l}\text { any amount different from normal } \\
\text { discharge with moistening of lids } \\
\text { discharge with moistening of considerable area } \\
\text { around eye }\end{array}$ & $\begin{array}{l}\mathbf{I} \\
2 \\
3\end{array}$ \\
\hline
\end{tabular}

\section{Results}

The results of photodynamic inactivation therapy in 22 rabbits with herpes simplex keratitis treated on Days 3 and 4 after inoculation are summarized in Fig. I (overleaf). This treatment regimen was selected as it had been found to provide the most satisfactory results in skin and mucocutaneous herpetic lesions. After development of marked signs of clinical infection, a gradual recovery period ensued which was characterized by decreased tearing and discharge, resolution of ciliary and conjunctival injection, and clearing of corneal infiltrates. No essential differences was found in the severity of keratitis in treated eyes compared with control eyes throughout the entire recovery period. This 2-week course of untreated herpes keratitis in the rabbit parallels previous reports on the natural course of the infection (Engle and Stewart, I964).

The results of therapy in fourteen rabbits treated for five successive days starting on Day 3 are summarized in Fig. 2 (overleaf). Again no therapeutic effect is observed when treated and control eyes are compared.

\section{Discussion}

While the phenomenon of photodynamic inactivation has been known since the turn of the century, this unique concept has been successfully applied to the management of infectious disease only in recent years. Positive results have been unequivocally demon- 


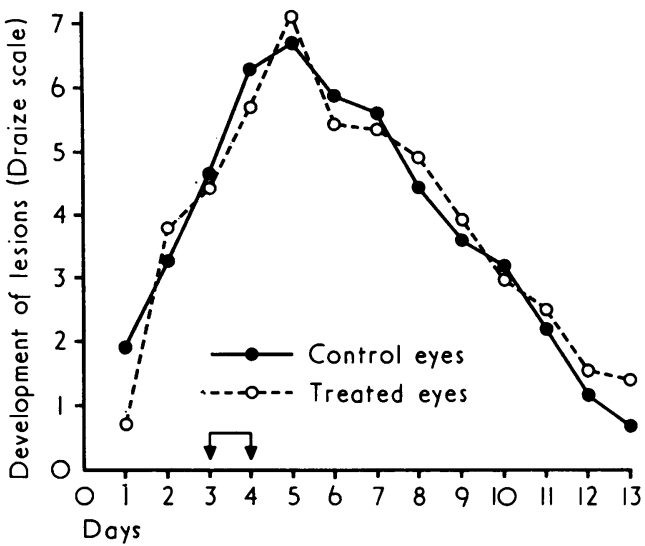

FIG. I Results in 22 rabbits treated on Days 3 and 4

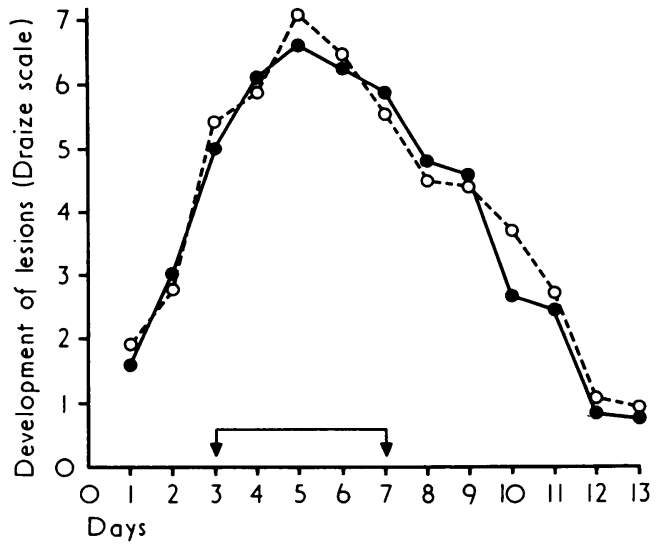

FIG. 2 Results in 14 rabbits treated on Days 3 to 7 inclusive

strated in the treatment of herpetic lesions of skin and mucocutaneous areas. The possibility that benefits might accrue in the treatment of herpes keratitis is enticing, but preliminary study has failed to substantiate this hope.

This study was limited in scope and design, and variables such as $\mathrm{pH}$, temperature, and removal of excess dye were not controlled. These are some of the factors that determine the occurrence of photodynamic inactivation in vitro (Wallis and Melnick, 1964). However, in the successful clinical study of herpes infections of the skin and mucosa carried out by Felber and others (197I), these variables were not controlled. It is not clear why herpes keratitis fails to show any response to this therapy.

The theory remains so attractive that the use of other photoactive dyes with the alteration of treatment variables merits further investigation before abandoning its potential use in ophthalmology.

\section{Summary}

A study was undertaken to determine the usefulness of photodynamic inactivation in treating herpes simplex keratitis. The data suggest that photodynamic inactivation has no effect on the natural course of experimental herpes simplex keratitis, but further work with other photoactive dyes is suggested.

\section{References}

Draize, J. H., WOODWARD, G., and Galvery, H. P. (I944) J. Pharmacol. exp. Ther., 82, 377 ENGLE, G. G., and STEWART, R. C. (1964) J. Immunol., 92, 730

Felber, T. D., WAllis, C. W., SMith, E. B., MElnick, J. L., and knox, J. M. (I97 I) Paper presented to the Scientific Assembly, AMA Section on Dermatology

FREIFELDER, D., and URETZ, R. B. (1966) Virology, 30, 97

PERdrau, J. R., and TODd, c. (1933) Proc. roy. Soc. B, I12, 288

RAAB, O. (1900) Z. Biol., 39, 524

SASTRY, K. s., and Gordon, M. P. (1966) Biochim. biophys. Acta (Amst.), 129, 32

SHORTT, H. E., and BROOKs, A. G. (1934) Indian 7. med. Res., 21, 581

WALlis, C., and MELNICK, J. L., (1964) Virology, 23, 520

- - (1965) Photochem. and Photobiol., 4, I59 